\title{
Lack of association between alopecia areata and HLA class I and II in a southeastern Brazilian population*
}

\author{
Ângela Marques Barbosa ${ }^{1}$ \\ Aldri Roberta Sodoschi Sobral ${ }^{2}$ \\ Bruna Cerávolo Lemos ${ }^{1}$ \\ Luciana Leite Crivelin Martos ${ }^{1}$
}

\author{
Luiz Euribel Prestes-Carneiro ${ }^{1}$ \\ Marcelo Jun Sakiyama ${ }^{2}$ \\ Marilda Aparecida Milanez Morgado de Abreu ${ }^{1}$ \\ Ricardo Alberto Moliterno ${ }^{2}$
}

DOI: http:/ / dx.doi.org/10.1590/abd1806-4841.20164250

\begin{abstract}
BACKGROUND: Alopecia areata (AA) is a common disorder of unknown etiology that affects approximately $0.7 \%$ to $3.8 \%$ of patients among the general population. Currently, genetic and autoimmune factors are emphasized as etiopathogenic. Studies linking Human Leukocyte Antigens (HLA) to AA have suggested that immunogenetic factors may play a role in the disease's onset/development.

Овлестіves: To investigate an association between AA and HLA class I/II in white Brazilians. Methods: Patients and control groups comprised 33 and 112 individuals, respectively. DNA extraction was performed by column method with BioPur kit. Allele's classification was undertaken using the PCR-SSO technique. HLA frequencies were obtained through direct counting and subjected to comparison by means of the chi-square test.

RESULTS: Most patients were aged over 16, with no familial history, and developed partial AA, with no recurrent episodes. Patients showed a higher frequency of HLA-B*40, HLA-B*45, HLA-B*53 and HLA-C*04 compared with controls, although $\mathrm{P}$ was not significant after Bonferroni correction. Regarding HLA class II, only HLA-DRB1*07 revealed statistical significance; nevertheless, it featured more prominently in controls than patients $(\mathrm{P}=0.04$; $\mathrm{PC}_{\mathrm{C}}=0.52 ; \mathrm{OR}=0.29 ; 95 \% ; \mathrm{CI}=0.07$ to 1.25$)$. $\mathrm{P}$ was not significant after Bonferroni correction.

Conclusions: The development of AA does not seem to be associated with HLA in white Brazilians, nor with susceptibility or resistance. The studies were carried out in populations with little or no miscegenation, unlike the Brazilian population in general, which could explain the inconsistency found.
\end{abstract}

Keywords: Alopecia areata; Genes, MHC Class I; Genes, MHC Class II.

\section{INTRODUCTION}

Alopecia areata (AA) is characterized by non-scarring loss of scalp hair or the loss of hair on other body areas. It is divided into three forms, depending on hair loss severity. The mildest form of AA involves incomplete hair loss of the scalp, known as incomplete alopecia or alopecia partialis (AP). It can progress to alopecia totalis (AT), total hair loss of the scalp, or alopecia universalis (AU), entailing total loss of scalp hair and body hair. ${ }^{1}$ The disease affects $0.7 \%$ to $3.8 \%$ of patients seen in dermatology clinics worldwide, occurring in both genders, with extreme variation in age range and progression. ${ }^{2}$ In the past, metabolic, psychological and vascular abnormalities were seen as etiopathogenic factors. ${ }^{3}$ Nowadays, autoimmune and genetic factors are believed to be responsible for the disease..$^{2-4}$

There is abundant evidence of the role played by immune mechanisms in AA, including the association with autoimmune diseases and the presence of circulating auto-antibodies. ${ }^{5}$ Thus, studies have been undertaken on the association between Human Leukocyte Antigen (HLA) and AA, suggesting that immunogenetic factors are involved in the disease's onset/ development. ${ }^{2,3,6}$ The molecular basis of this associa-

Received on 26.11.2014.

Approved by the Advisory Board and accepted for publication on 19.07.2015.

Work performed at the Dermatology Service, Hospital Regional de Presidente Prudente - Universidade do Oeste Paulista (UNOESTE) and Laboratory of

Immunogenetics, Department of Health Basic Sciences, Universidade Estadual de Maringá (UEM) - Maringá (PR), Brazil.

Financial Support: Universidade do Oeste Paulista, CAPES and Immunogenetics Laboratory of Universidade Estadual de Maringá.

Conflict of Interest: None.

Universidade do Oeste Paulista (UNOESTE) - Presidente Prudente (SP), Brazil.

Universidade Estadual de Maringá (UEM) - Maringá (PR), Brazil.

(C)2016 by Anais Brasileiros de Dermatologia 
tion lies in the fact that HLA molecules bind to and present peptide antigens, derived from the organism itself, as well as peptides derived from etiologic agents for CD4 + and CD8 + lymphocytes. ${ }^{7,89}$ No studies on AA patients in the white Brazilian population have been conducted so far. Hence, the aim of this study was to investigate an association between AA and HLA class I/class II in white Brazilians.

\section{OBJECTIVES}

Our aim was to investigate an association between AA and HLA class I/II in white Brazilians.

\section{METHODS}

\section{Patient selection}

This is a cross-sectional study of 33 white, Brazilian patients seen by dermatologists at the Dermatology Ambulatory of the Presidente Prudente Regional Hospital, São Paulo State, Brazil. One hundred and twelve healthy, white, Brazilian individuals with no history of AA were selected for the control group. They were matched with patients by gender, age and ethnic group. Patients answered an epidemiological questionnaire, providing information on: their age, gender, ethnicity, AA type (AP, AT and AU), age at AA onset (early onset: < 16 years, late onset: $\geq 16$ years), associated diseases such as thyroid diseases, diabetes, systemic lupus erythematosus, and personal and family history (we looked for evidence of AA in patients with relatives up to the third degree).

\section{Determination of laboratory markers associat- ed with autoimmune diseases}

The association between AA and some of the more prevalent markers of autoimmune diseases was investigated. IgE antibodies were determined by chemiluminescence; antinucleus antibodies (ANA) were determined by immunofluorescence; while thyroid stimulant hormone (TSH), T4 and anti-thyroglobulin (anti-TG) were determined by electrochemiluminescence, in accordance with the manufacturer's instructions.

\section{HLA typing}

Blood samples $(5 \mathrm{ml})$ were collected from patients and controls to determine HLA specificities (low/medium resolution). The blood was stored in tubes containing EDTA and sent to Maringá State University's Immunogenetic Laboratory, Maringá, Paraná, Brazil.

Genomic DNA was extracted through the column extraction technique using the Biopur ${ }^{\circledR}$ Kit (Biometrix, Curitiba, PR, Brazil), following the manufacturer's instructions. HLA typing was performed with the PCR-SSO RELI technique (Dynal RELITM SSO Carlsbad, CA, United States) for HLA-A, B and DRB1 genes, and
SSO Luminex ${ }^{\circledast}$ (One Lambda, Canoga Park, CA, USA) or HLA-C, DQA1 and DQB1 genes.

This study was registered and approved by the University of Oeste Paulista's ethics committee for research involving human subjects, under Number 045/ OL/2009, Presidente Prudente, São Paulo State, Brazil. All participants signed an informed consent.

\section{Statistical analysis}

Allele frequencies were obtained by direct counting and compared by $2 \times 2$ contingency tables using the chi-square test and Fisher's exact test. Only $P$ values $<0.05$ were significant. Significant $P$ values were corrected by the number of specificities tested at each locus (Pc; Bonferroni correction). Statistical analyses were carried out using the SISA statistics software (http://www.quantitativeskills.com/sisa/). The Hardy-Weinberg equilibrium was calculated through the Arlequin software.

\section{RESULTS}

Patients characteristics

The following patient characteristics are described in Table 1: age, gender at the onset, AA form, number of episodes, presence of associated diseases and family history. Most patients were men aged over 16 , with no familial history of the disease. There was a prevalence of partialis AA with no recurrent episodes,

TABLE 1: Clinical characteristics of 33 patients with alopecia areata and 112 controls, seen by dermatologists at the Dermatology Ambulatory of the Presidente Prudente Regional Hospital, São Paulo State, Brazil

\begin{tabular}{lll}
\hline Clinical Parameters & Patients n=33 & Controls n=112 \\
\hline Age (means \pm SD) & $36.70 \pm 18.0$ & $31.67 \pm 13.86$ \\
Gender (\% & $17(51.2)$ & $49(43.7)$ \\
Male & $16(48.5)$ & $63(56.3)$ \\
Female & & \\
AA type & $24(72.7)$ & - \\
AP & $4(12.1)$ & - \\
AT & $5(15.2)$ & - \\
AU & & \\
Episodes & $12(27.4)$ & - \\
Single & $21(63.6)$ & - \\
Recurrent & $7(21.2)$ & - \\
Associated diseases & $26(78.8)$ & - \\
Presence & $7(21.2)$ & - \\
Absence & $31(93.9)$ & - \\
Family cases &
\end{tabular}

$\mathrm{AA}=$ alopecia areata; $\mathrm{AP}=$ alopecia partialis $\mathrm{AT}=$ alopecia totalis and $\mathrm{AU}=$ alopecia universalis 
and no significant differences between patients and control groups regarding age and gender. The sample population exhibited the Hardy-Weinberg equilibrium. Among the onset associated diseases reported by patients, the presence of Hashimoto thyroiditis was significantly higher in patients than in controls (14\% vs. $1.8 \%, \mathrm{P}=0.001)$. Laboratory markers of auto-immune diseases showed no differences in ANA or IgE levels in AA patients compared with controls, while TSH, T4 and anti-TG all appeared at normal levels in both groups (data not shown).

\section{HLA class I}

Table 2 compares the frequency of HLA class I in patients and controls. Patients demonstrated a higher frequency of HLA-B*40, HLA-B*45, HLA-B*53 and
HLA-C ${ }^{*} 04$ than controls, although $\mathrm{P}$ was not significant after Bonferroni's correction: (HLA-B $* 40 \mathrm{P}=0.02$; $\mathrm{PC}_{\mathrm{C}}=0.56, \mathrm{OR}=3.63 ; 95 \% ; \mathrm{CI}=1.13$ to 11.67$)$; $\left(\mathrm{HLA}-\mathrm{B}^{*} 45\right.$, $\mathrm{P}=0.01 ; \mathrm{PC}_{\mathrm{C}}=0.28, \mathrm{OR}=6.04 ; 95 \% ; \mathrm{CI}=1.40$ to 25.98$)$; (HLA-B $* 53 \mathrm{P}=0.03 ; \mathrm{Pc}=0.84, \mathrm{OR}=10.62 ; 95 \% ; \mathrm{CI}=$ 1.09 to 103.86); (HLA-C ${ }^{*} 04 ; \mathrm{P}=0.04 ; \mathrm{Pc}=0.56 ; \mathrm{OR}=$ $2.01 ; 95 \% ; C I=1.03$ to 3,90$)$. No statistical differences were observed for the locus A specificities ( $p>0.05)$.

\section{HLA class II}

Table 3 displays the results for HLA class II. Only HLA-DRB1*07 showed statistical significance; nevertheless, it was more frequent in controls than in patients $\left(\mathrm{P}=0.04 ; \mathrm{PC}_{\mathrm{C}}=0.52 ; \mathrm{OR}=0.29 ; 95 \% ; \mathrm{CI}=0.07\right.$ to 1.25). Once again, $P$ was not significant after Bonferroni's correction.

TABLE 2: Distribution of HLA class I specificities in 33 AA patients and 112 controls, seen at the Dermatology Ambulatory of the Presidente Prudente Regional Hospital, São Paulo State, Brazil

\begin{tabular}{|c|c|c|c|c|c|c|c|c|}
\hline \multicolumn{3}{|l|}{ HLA-A } & \multicolumn{3}{|l|}{ HLA-B } & \multicolumn{3}{|l|}{ HLA - C } \\
\hline Allele Groups & $\begin{array}{l}\text { Patients } \\
\mathbf{n}(\mathbf{f})\end{array}$ & $\begin{array}{l}\text { Controls } \\
\mathbf{n}(\mathbf{f})\end{array}$ & Allele Groups & $\begin{array}{l}\text { Patients } \\
\mathbf{n}(\mathbf{f})\end{array}$ & $\begin{array}{l}\text { Controls } \\
\text { n(f) }\end{array}$ & Allele Groups & $\begin{array}{l}\text { Patients } \\
\mathbf{n}(\mathbf{f})\end{array}$ & $\begin{array}{l}\text { Controls } \\
\mathrm{n}(\mathrm{f})\end{array}$ \\
\hline$A^{*} 01$ & $05(7.6)$ & $20(8.9)$ & B*07 & 07(10.6) & $22(9.8)$ & $C^{*} 01$ & $00(0.0)$ & $07(3.1)$ \\
\hline $\mathrm{A}^{*} 02$ & 19(28.8) & $61(27.2)$ & $B^{*} 08$ & $02(3.0)$ & $14(6.2)$ & $C^{*} 02$ & $05(7.6)$ & $14(6.2)$ \\
\hline$A^{*} 03$ & 08(12.1) & $26(11.6)$ & $B^{*} 13$ & $00(0.0)$ & $03(1.3)$ & $C^{*} 03$ & 07(10.6) & $20(8.9)$ \\
\hline$A^{*} 11$ & $03(4.5)$ & $09(4.0)$ & $B^{*} 14$ & $01(1.5)$ & $16(7.1)$ & $C^{*} 04^{d}$ & $17(25.8)$ & $33(14.7)$ \\
\hline$A * 23$ & $03(4.5)$ & $10(4.4)$ & $B^{*} 15$ & $05(7.6)$ & $14(6.2)$ & $C^{*} 05$ & $04(6.1)$ & $05(2.2)$ \\
\hline$A * 24$ & 07(10.6) & $24(10.7)$ & $B^{*} 18$ & $03(4.5)$ & $17(7.6)$ & $C^{*} 06$ & $01(1.5)$ & $14(6.2)$ \\
\hline$A^{*} 25$ & $01(1.5)$ & $05(2.2)$ & $B * 27$ & $00(0.0)$ & $01(0.4)$ & $C^{*} 07$ & $16(24.2)$ & $61(27.2)$ \\
\hline$A * 26$ & $01(1.5)$ & $11(4.9)$ & $B * 35$ & $10(15.1)$ & $31(13.8)$ & $C^{*} 08$ & $01(1.5)$ & $14(6.2)$ \\
\hline$A * 29$ & $03(4.5)$ & $17(7.6)$ & $B * 37$ & $00(0.0)$ & $04(1.8)$ & $C^{*} 12$ & $05(7.6)$ & $21(9.4)$ \\
\hline$A * 30$ & $04(6.1)$ & $05(2.2)$ & $B * 38$ & $02(3.0)$ & $07(3.1)$ & $C^{*} 14$ & $00(0.0)$ & $09(4.0)$ \\
\hline$A * 31$ & $03(4.5)$ & $13(5.8)$ & $B * 39$ & $02(3.0)$ & $07(3.1)$ & $C^{*} 15$ & $04(6.1)$ & $09(4.0)$ \\
\hline$A^{*} 32$ & $04(6.1)$ & $04(1.8)$ & $B * 40^{\mathrm{a}}$ & $06(9.1)$ & $06(2.7)$ & $C^{*} 16$ & $04(6.1)$ & $14(6.2)$ \\
\hline$A * 33$ & $01(1.5)$ & $04(1.8)$ & $B^{*} 41$ & $00(0.0)$ & $02(0.9)$ & $C^{*} 17$ & $01(1.5)$ & $01(0.4)$ \\
\hline$A^{*} 66$ & $00(0.0)$ & $02(0.9)$ & B*42 & $01(1.5)$ & $01(0.4)$ & $C^{*} 18$ & $01(1.5)$ & $02(0.9)$ \\
\hline$A^{*} 68$ & $03(4.5)$ & $11(4.9)$ & $B^{*} 44$ & $05(7.6)$ & $27(12.0)$ & & & \\
\hline$A^{* 69}$ & $00(0.0)$ & $01(0.4)$ & $B^{*} 45^{b}$ & $05(7.6)$ & 03(1.3) & & & \\
\hline$A^{* 74}$ & $01(1.5)$ & $01(0.4)$ & $B * 47$ & $00(0.0)$ & $01(0.4)$ & & & \\
\hline & & & $B * 48$ & $00(0.0)$ & $02(0.9)$ & & & \\
\hline & & & $B * 49$ & $01(1.5)$ & $05(2.2)$ & & & \\
\hline & & & $B * 50$ & $00(0.0)$ & $04(1.8)$ & & & \\
\hline & & & $B * 51$ & $07(10.6)$ & $22(9.8)$ & & & \\
\hline & & & $B * 52$ & $01(1.5)$ & $02(0.9)$ & & & \\
\hline & & & $B^{*} 53^{c}$ & $03(4.5)$ & $01(0.4)$ & & & \\
\hline & & & B $* 55$ & $00(0.0)$ & 03(1.3) & & & \\
\hline & & & $B * 56$ & $00(0.0)$ & $02(0.9)$ & & & \\
\hline & & & $B * 57$ & $02(3.0)$ & 03(1.3) & & & \\
\hline & & & $B * 58$ & $03(4.5)$ & 03(1.3) & & & \\
\hline & & & $B^{*} 78$ & $00(0.0)$ & $01(0.4)$ & & & \\
\hline
\end{tabular}

$\mathrm{n}=$ number of specificities; $(\mathrm{f})=$ frequency of specificities; $\mathrm{OR}=$ odds ratio; $\mathrm{CI}=$ confidence interval; $\mathrm{Pc}=\mathrm{P}$ corrected;

${ }^{a} H L A-B * 40: 9.1$ vs 2.7; $\mathrm{P}=0.02 ; \mathrm{PC}=0.56 ; \mathrm{OR}=3.63 ; 95 \% ; \mathrm{CI}=1.13-11.67$. ${ }^{\circ} \mathrm{HLA}-\mathrm{B}^{*} 45: 7.6$ vs $1.3 ; \mathrm{P}=0.01 ; \mathrm{PC}=0.28 ; \mathrm{OR}=6.04 ; 95 \% ; \mathrm{CI}=1.40-25.98 .{ }^{\mathrm{c}} \mathrm{HLA}-\mathrm{B}^{*} 53$ : 4.5 vs 0.4; $\mathrm{P}=0.03 ; \mathrm{PC}=0.84 ; \mathrm{OR}=10.62 ; 95 \% ; \mathrm{CI}=1.09-103.86 .{ }^{\mathrm{d}} \mathrm{HLA}-\mathrm{C}^{*} 04: 25.8$ vs $14.7 ; \mathrm{P}=0.04 ; \mathrm{PC}=0.56 ; \mathrm{OR}=2.01 ; 95 \% ; \mathrm{CI}=1.03-3.90$. 
TABLE 3: Distribution of HLA class II specificities in 33 AA patients and 112 controls, seen at the Dermatology Ambulatory of the Presidente Prudente Regional Hospital, São Paulo State, Brazil

\begin{tabular}{llllll}
\hline Allele Group & Patients $\mathbf{n}(\mathbf{f})$ & Controls n(f) & Alleles & Patients n(f) & Controls n(f) \\
\hline DRB1 & & & DQA1 & & \\
DRB1*01 & $06(9.1)$ & $20(8.9)$ & DQA1*01 & $31(46.9)$ & $34(50.0)$ \\
DRB1*03 & $06(9.1)$ & $22(9.8)$ & DQA1*02 & $02(3.0)$ & $06(8.8)$ \\
DRB1*04 & $08(12.1)$ & $25(11.2)$ & DQA1*03 & $09(13.6)$ & $06(8.8)$ \\
DRB1*07 & $02(3.0)$ & $22(9.8)$ & DQA1*04 & $03(4.5)$ & $03(4.4)$ \\
DRB1*08 & $04(6.1)$ & $14(6.2)$ & DQA1*05 & $21(31.8)$ & $19(27.9)$ \\
DRB1*09 & $01(1.5)$ & $03(1.3)$ & & & \\
DRB1*10 & $01(1.5)$ & $06(2.7)$ & DQB1 & & \\
DRB1*11 & $13(19.7)$ & $35(15.6)$ & DQB1*02 & $08(12.1)$ & $15(22.1)$ \\
DRB1*12 & $01(1.5)$ & $05(2.2)$ & DQB1*03 & $25(37.9)$ & $16(23.5)$ \\
DRB1*13 & $12(18.2)$ & $25(11.2)$ & DQB1*04 & $02(3.0)$ & $03(4.4)$ \\
DRB1*14 & $01(1.5)$ & $12(5.4)$ & DQB1*05 & $14(21.2)$ & $20(29.4)$ \\
DRB1*15 & $06(9.1)$ & $26(11.6)$ & DQB1*06 & $17(25.8)$ & $14(20.6)$ \\
DRB1*16 & $05(7.6)$ & $09(4.0)$ & & & \\
\hline
\end{tabular}

$\mathrm{n}=$ number of specificities; $(\mathrm{f})=$ frequency of specificities; $\mathrm{OR}=$ odds ratio

$\mathrm{CI}=$ confidence of interval; $\mathrm{PC}=\mathrm{P}$ corrected; ${ }^{\mathrm{a}} \mathrm{HLA}-\mathrm{DRB1}{ }^{*} 07: 3.0$ vs 9.8; $\mathrm{P}=0.04 ; \mathrm{PC}=0.52 ; \mathrm{OR}=0.29 ; 95 \% ; \mathrm{CI}=0.07-1.25$.

\section{DISCUSSION}

AA is considered a disease with a broad spectrum of clinical features and variable age of onset. Genome-wide associations have shown that the disease is strongly linked to Major Histocompatibility Complex (MHC), although associated loci outside HLA have also been implicated in AA's pathogenesis. ${ }^{10}$ This study describes the distribution of HLA class I and II in white AA Brazilian patients. Comparing AA and control patients, there was no statistical difference between HLA class I and II allele distribution after Bonferroni's correction.

The role of HLA class II genes in the pathogenesis of AA was overwhelmingly highlighted in the literature. ${ }^{7,10}$ In this study, only HLA-DRB1*07 exhibited a statistical significance; nevertheless, it was more frequent in controls than in patients $(\mathrm{P}=0.04)$, although $\mathrm{P}$ was not significant after correction. Recently, a wide-genome meta-analysis examined a total of 2,489 AA patients and 5,287 controls, identifying four variants in HLA-DRA and HLA-DRB1 genes. The authors demonstrated the pivotal role of HLA class II genes and particularly of HLA-DRB1 in the etiopathogenic pathogenesis of AA. ${ }^{10}$ Our findings are different from those of some studies conducted in AA patients, which found both increased and decreased specificity in DRB1 genes associated with AA. In Turkey, Akar et al. observed a significant decrease in DRB1*03 specificity - but an increase in DRB1*04 specificity - in individuals affected by AA, depending on the intensity of hair loss. ${ }^{9}$ Furthermore, a study carried out in California by Colombe et al. uncovered increased levels of DRB1*11:04 and DRB1*04:01 alleles; however, the latter was high only in the AT/AU group, suggesting that in the population analyzed, this allele may indicate a more severe AA genetic susceptibility. ${ }^{11}$

This study found no association between DQ class II genes and AA. Significant increases in allele frequencies of HLA-DQA1*01:04, DQB1*06:04 and DQB1*06:06 were described by Xiao et al. in Chinese patients, both in early- and late-onset disease. ${ }^{12}$ In Turkey, a significant increase in HLA-DQB01*03 was identified compared with controls, leading to the conclusion that DQB1*03 is a general marker of AA susceptibility in the country's population. ${ }^{9}$ Similar results were described in North Americans. ${ }^{11}$ Importantly, it was only for DQB1*06:04 and DQB1*06:06 in Chinese patients that the association with AA remained significant after Bonferroni's correction. ${ }^{12}$

Recently, an association was suggested between a new MHC class II candidate gene and AA development. Using exome sequencing, it was suggested in a Korean population diagnosed with AU, the involvement of HLA-DRB5. The HLA-DRB5 genes encode the class II MHC complex and are involved in antigen emergence by antigen-presenting cells. Further, the gene is related in several autoimmune diseases, such as multiple sclerosis, systemic sclerosis and rheumatic heart disease. ${ }^{13}$

Studies on HLA class I molecules are scarce and have yielded controversial results. In this study, no statistical differences were observed for the locus A specificities $(p>0.05)$. As highlighted for class II HLA genes, the results are different from those of other populations. Xiao et al. ${ }^{12}$ observed significantly increased fre- 
quencies for HLA-A*02 and HLA-A*03 in a study with Chinese patients, whereas in the Turkish sample, significance was only identified for HLA-A ${ }^{*} 01 .{ }^{3}$ Regarding HLA-B, we found a higher frequency of HLA-B ${ }^{*} 40$, HLA-B ${ }^{*} 45$, HLA-B ${ }^{*} 53$ compared with controls, but, as with HLA class II genes, no statistical significance was found after Bonferroni's correction. The Turkish sample revealed significance for HLA- $B^{*} 62^{3}$, while in Chinese patients, increased frequencies were found for HLA-B*17, $B^{*} 18$ and $B * 52$. However, in both studies, no statistical differences remained following Bonferroni's correction. ${ }^{12}$ As for HLA-C, few published data are available. In our sample, only the HLA-C*04 specificity was more frequent in patients than in controls before Bonferroni's correction. In Chinese individuals, Xiao et al. identified an association between AA and HLA-C*07:04. ${ }^{12,14}$ In both cases, similarly to our data, no significant statistical differences were found after Bonferroni's correction. Recently, in a Japanese population of 157 individuals with AA, a strong association with $C^{*} 04: 01$ and $C^{*} 15: 02$ was described. ${ }^{15}$ The variability concerning class I and class II gene specificities in AA patients of different countries could be attributed to the populations' various genetic predispositions, as well as the influence of different behaviors, environmental and ethnic factors. ${ }^{10}$

Our study is limited because of the low number of patients due to difficulties in selecting AA patients and controls matched by ethnicity, gender and age. The cornerstone ethnic and racial composition of Brazil's population results from a confluence of many different ethnic backgrounds: indigenous peoples, black Africans, Portuguese colonizers, and subsequent waves of Europeans, Arabs, Japanese, as well as people from other Asian and South American countries. According to the Brazilian Institute of Geography and Statistic (IBGE), in 2010, Brazil's population was composed as follows: $47.7 \%$ white, $7.6 \%$ black, $43.1 \%$ brown or "pardos", $1 \%$ yellow and $0.4 \%$ indigenous. ${ }^{16}$

AA has been linked to autoimmune diseases, while significant associations with different comorbidities have been made, including: vitiligo, lupus erythematosus, psoriasis, atopic dermatitis, type I and type II diabetes, autoimmune thyroid disease, Down syndrome and allergic rhinitis. ${ }^{10,17}$ In this study, only Hashimoto thyroiditis was significantly higher in patients compared with controls $(\mathrm{P}=0.007)$.

\section{CONCLUSION}

The development of AA does not seem to be strongly associated with HLA in white Brazilians, nor with susceptibility or resistance. Our data did not confirm the previous findings in the literature. However, most of the AA/HLA gene associations were carried out in populations with little or no miscegenation, unlike the Brazilian population, thus leading to strong genetic variability, which could explain the data discrepancies/inconsistencies found. The study's small sample size is its main shortcoming; thus, further studies with larger population samples are recommended.

\section{ACKNOWLEDGMENTS}

To all volunteers who took part in this study. 


\section{REFERENCES}

1. Alkhalifah A. Alopecia areata update. Dermatol Clin. 2013;31:93-108.

2. Alkhalifah A, Alsantali A, Wang E, McElwee KJ, Shapiro J. Alopecia areata update: part I. Clinical picture, histopathology, and pathogenesis. J Am Acad Dermatol 2010;62:177-88

3. Kavak A, Baykal C, Ozarmağan G, Akar U. HLA in alopecia areata. Int J Dermatol. 2000;39:589-92

4. Gilhar A, Kalish RS. Alopecia areata: a tissue specific autoimmune disease of the hair follicle. Autoimmun Rev. 2006;5:64-9.

5. Rivitti EA. Alopecia areata: revisão e atualização. An Bras Dermatol. 2005;80:5768.

6. Huang KP, Mullangi S, Guo Y, Qureshi AA. Autoimmune, atopic, and mental health comorbid conditions associated with alopecia areata in the United States. JAMA Dermatol. 2013;149:789-94.

7. Barahmani N, de Andrade M, Slusser JP, Wei Q, Hordinsky M, Price VH, et al. Human leukocyte antigen class II alleles are associated with risk of alopecia areata. J Invest Dermatol. 2008;128:240-3.

8. McElwee KJ, Gilhar A, Tobin DJ, Ramot Y, Sundberg JP, Nakamura M, et al. What causes alopecia areata? Exp Dermatol. 2013;22:609-26.

9. Akar A, Orkunoglu E, Sengül A, Ozata M, Gür AR. HLA class II alleles in patients with alopecia areata. Eur J Dermatol. 2002;12:236-9.

10. Betz RC, Petukhova L, Ripke S, Huang H, Menelaou A, Redler S, et al.Genomewide meta-analysis in alopecia areata resolves HLA associations and reveals two new susceptibility loci. Nat Commun. 2015;6:5966.

11. Colombe BW, Lou CD, Price VH. The genetic basis of alopecia areata: HLA associations with patchy alopecia areata versus alopecia totalis and alopecia universalis. J Investig Dermatol Symp Proc. 1999;4:216-9.

12. Xiao FL, Ye DQ, Yang S, Zhou FS, Zhou SM, Zhu YG, et al. Association of HLA haplotype with alopecia areata in Chinese Hans. J Eur Acad Dermatol Venereol. 2006;20:1207-13.

13. Lee S, Paik SH, Kim HJ, Ryu HH, Cha S, Jo SJ, et al. Exomic sequencing of immune-related genes reveals novel candidate variants associated with alopecia universalis. PLoS One. 2013;8:e53613.

14. Xiao FL, Zhou FS, Liu JB, Yan KL, Cui Y, Gao M, et al. Association of HLA-DQA1 and DQB1 alleles with alopecia areata in Chinese Hans. Arch Dermatol Res. 2005;297:201-9.

15. Haida Y, Ikeda S, Takagi A, Komiyama E, Mabuchi T, Ozawa A, et al. Association analysis of the HLA-C gene in Japanese alopecia areata. Immunogenetics. 2013;65:553-7.

16. dssbr.org/site [Internet]. Instituto Brasileiro de Geografia e Estatística. A nova composição racial brasileira segundo o Censo 2010. [acesso 30 abr 2015]. Disponivel em: http://dssbr.org/site/2012/01/a-nova-composicao-racialbrasileira-segundo-0-censo-2010/

17. Estefan JL, Oliveira JC, Abad ED, Saintive SB, Porto LC, Ribeiro M. HLA antigens in individuals with Down syndrome and alopecia areata. World J Clin Cases. 2014;2:541-5.
MAILING ADDRESS:

Luiz Euribel Prestes-Carneiro

Hospital Regional de Presidente Prudente,

Rua José Bongiovani, 1297 - Presidente Prudente

19050-680 - Sao Paulo - SP

Brazil

E-mail:luiz@unoeste.br

How to cite this article: Barbosa AM, Prestes-Carneiro LE, Sobral ARS, Sakiyama MJ, Lemos BC, Abreu MAMM, Martos LLC, Moliterno RA . Lack of association between alopecia areata and HLA class I and II in a southeastern Brazilian population. An Bras Dermatol. 2016;91(3):284-9. 